\title{
Myocardial infarction related to valve replacement surgery
}

\author{
C G A McGREGOR, M D MAcLEOD, A L MUIR, A F SMITH, W J HANNAN, \\ H C MILLER \\ From the Departments of Clinical Surgery, Medicine, Medical Physics, and Clinical Chemistry, University of \\ Edinburgh, and the Department of Cardiology, Royal Infirmary, Edinburgh
}

SUMMARY Fifty consecutive patients, 25 undergoing aortic valve replacement and 25 mitral valve replacement, were studied by serial electrocardiography, preoperative and postoperative technetium-99m pyrophosphate radionuclide scanning, and serial measurement of enzymes (creatine kinase, aspartate aminotransferase, urea stable lactic dehydrogenase) and the MB isoenzyme of creatine kinase to define the incidence of peroperative myocardial infarction and to identify the most appropriate diagnostic techniques. The use of myocardial scanning and measurement of peak enzyme activity proved to be accurate indicators of myocardial infarction, but the electrocardiogram was of limited value. The measurement of creatine kinase MB isoenzyme had no diagnostic advantage over that of the other enzymes. There were two deaths in the series, one due to acute pancreatitis after aortic valve replacement and the other due to myocardial injury after mitral valve replacement. There were four non-fatal myocardial infarctions after aortic valve replacement, giving an incidence of $16 \%$, and none after mitral valve replacement, giving an incidence of $4 \%$.

Peroperative myocardial infarction is the major cause of mortality and morbidity after cardiac valve replacement. ${ }^{12}$ There continues to be a great research effort into improving methods of protecting the heart from such injury sustained during the period of global myocardial ischaemia when the aorta is cross clamped during replacement of the valve. ${ }^{3-5}$ The importance of the length of the aortic clamping time has been stressed by Stiles and Kirklin. ${ }^{5}$ A "safe" time limit for aortic cross clamping will vary according to operative factors such as the method of myocardial protection used and the preoperative clinical and haemodynamic status of the patient. ${ }^{5}$ No single best method of myocardial protection is agreed, and, although the operative mortality for aortic valve replacement has declined, there remains a high incidence of operative myocardial injury. Varying estimates of the incidence of between $4 \%$ and $26 \%$ have been reported after aortic valve replacement ${ }^{6-8}$ and of between $0 \%$ and $13 \%$

Requests for reprints to Mr C G A McGregor, FRCS, Department of Cardiovascular Surgery, Stanford University Medical Center, 300 Pasteur Drive, Stanford, California 94305, USA.

^Dr Michael D MacLeod died on 31 May 1983.

Accepted for publication 17 January 1984 after mitral valve replacement. ${ }^{910}$ The varying incidence can in part be attributed to different methods of assessing injury. A reliable and reproducible method of diagnosing peroperative myocardial infarction is required to assess the impact of continually improving methods of myocardial protection. Many studies of methods of assessing myocardial damage continue to be reported.11-13 Some have studied high risk patients in an attempt to exaggerate differences in methods of myocardial preservation. ${ }^{14}$

The problems of electrocardiographic interpretation in the postoperative period are well recognised. ${ }^{91516}$ The measurement of the MB isoenzyme of creatine kinase has been shown to be a good marker of myocardial damage after valve replacement ${ }^{11}$ and to correlate with other methods of identifying damage after other cardiac surgical procedures, ${ }^{17-19}$ but its value has been questioned by others. ${ }^{91820}$ The use of technetium-99m pyrophosphate myocardial scanning has proved to be a valuable technique for the diagnosis of peroperative myocardial infarction 152021 and may indicate a much higher incidence of infarction than would otherwise be suspected.22 To define the incidence of myocardial infarction and to allow comparison of the diagnostic methods used we investigated in parallel the application of technetium-99m 
pyrophosphate scanning, the measurement of enzyme and isoenzyme activity, and serial electrocardiography in 50 patients, 25 undergoing aortic valve replacement and 25 mitral valve replacement.

\section{Patients and methods}

\section{STUDY POPULATION}

Fifty consecutive patients, 25 undergoing aortic valve replacement and 25 mitral valve replacement as the sole procedure, were studied. The mean age of patients undergoing aortic valve replacement was 55 (range 26-71) years. Sixteen of these patients had undergone selective coronary arteriography preoperatively, which showed no significant coronary artery disease in any of the patients. Thirteen had aortic stenosis, three aortic regurgitation, and nine mixed aortic valve disease. The mean age of patients undergoing mitral valve replacement was 57 (range 13-72) years. In all patients their symptoms were in New York Heart Association classification III or IV. Nine of these patients had selective coronary arteriograms preoperatively, in six of whom there was no significant coronary artery disease. Two patients had mild $(<50 \%)$ stenosis in a single vessel and one an absent left coronary orifice.

\section{OPERATIVE TECHNIQUES}

Standard cardiopulmonary bypass techniques were used at flow rates of $2.41 / \mathrm{m}^{2} / \mathrm{min}$. The mean cardiopulmonary bypass and aortic cross clamping time for those patients having aortic valve replacement was 95 (range 61-261) minutes and 67 (range 41-207) minutes respectively and for those having mitral valve replacement 71 (range 55-100) minutes and 49 (range 38-92) minutes respectively. The technique of myocardial preservation was cold potassium cardioplegic arrest with topical cooling using $4^{\circ} \mathrm{C}$ normal saline and systemic hypothermia of $28^{\circ} \mathrm{C}$.

\section{ELECTROCARDIOGRAPHY}

Electrocardiograms were recorded preoperatively and daily postoperatively until discharge and were assessed blind by a cardiologist. The appearance of new $Q$ waves of $\geqslant 0.04 \mathrm{~s}$ duration was regarded as indicative of myocardial infarction.

\section{ENZYMES}

Creatine kinase and aspartate aminotransferase-These were measured by standard techiques. ${ }^{23}$ The upper limit of normal for non-ambulant healthy subjects is $150 \mathrm{U} / 1$ and $30 \mathrm{U} / \mathrm{l}$ respectively.

Creatine kinase $(M B)$ isoenzyme was measured using a slight modification of the chromatographic method of Mercer $^{24}$ using kit reagents (supplied by Boehringer Corporation, Lewes). The upper limit of normal for non-ambulant healthy subjects is $10 \mathrm{U} / 1$.

Urea stable lactate dehydrogenase was measured using a slight modification of a previously published method. ${ }^{25}$ The upper limit of normal for healthy adults is $300 \mathrm{U} / 1$.

Analytical precision was $5 \%$ (coefficient of variation) for enzyme activities for each enzyme in the ranges encountered in this study. The above enzymes were measured preoperatively and on seven subsequent occasions in the first $\mathbf{4 8}$ hours postoperatively, immediately after the bypass procedure and at 3,6, 9, 12,24 , and 48 hours after the bypass procedure.

To normalise the distribution and equalise the variances, the data for each enzyme were subjected to logarithmic transformation, and subsequent manipulations were carried out on $\log$ transformed data. Comparison was made between each enzyme in its ability to discriminate those patients who had had a myocardial infarction on the basis of a positive myocardial scan. Increases in peak serum creatine kinase (MB) enzyme activity were regarded as positive for myocardial infarction if values exceeded the mean ( \pm 2 standard deviations $( \pm 2 S D)$ ) for the log transformed data from those patients in whom the scan was negative; in this study this figure was $95 \mathrm{U} / 1$. One patient was excluded from this statistical analysis since the enzyme result for this patient was obviously outlying the results from other patients in the group and was inconsistent with the other enzyme findings for this patient.

\section{MYOCARDIAL SCANNING}

Analogue and digital images using technetium-99m pyrophosphate were obtained two hours after an intravenous injection of $400 \mathrm{MBq}$ in the anterior, $30^{\circ}$ and $60^{\circ}$ left anterior oblique, and left lateral projections with the patient in a supine position using a Nuclear Enterprise Mk5 HR gammacamera.

Radionuclide scans were performed preoperatively in the last 18 patients undergoing aortic valve replacement and the last 17 undergoing mitral valve replacement. All 48 patients completing the study had scans recorded two to five days postoperatively. All scans were assessed blind by two observers. Scans were graded into those showing no activity $(-)$, increased activity over the region of the heart but of less intensity than surrounding bone $( \pm)$, and increased activity over the heart of equal or greater intensity than bone $(+)$. Only results in the third category were accepted as true positives and had to be present in two of the four views.

\section{Results}

All 35 preoperative scans were negative. Preoperative enzyme activities were not appreciably raised in any of 
the 50 patients. One patient undergoing aortic valve replacement died of acute haemorrhagic pancreatitis on the third postoperative day having been well immediately after operation. There was no enzymatic or electrocardiographic evidence of myocardial injury in this patient. In the other 24 patients undergoing aortic valve replacement there was no evidence of myocardial infarction in 16 patients when any of the criteria used in the study were applied. One patient undergoing mitral valve replacement died of low cardiac output in the immediate postoperative period. She was considered to have sustained myocardial injury at the time of operation incompatible with the maintenance of a circulation.

Table 1 shows those remaining eight patients undergoing aortic valve replacement who had evidence of myocardial infarction by at least one criterion-that is, electrocardiographic or scan evidence or peak isoenzyme activity equal to or greater than the mean $( \pm 2 S D)$ for the group. The creatine kinase (MB) isoenzyme values are shown, but the other enzymes showed similar, or nearly similar, results.

In case 7 there was loss of $R$ wave in the inferior leads with a $Q S$ pattern, but the $Q$ waves did not persist. In case 14 the electrocardiogram showed left bundle branch block postoperatively with the development of a QS pattern in the inferior leads, but after 10 days the recording had changed little from the preoperative tracings.

Table 2 compares the positive findings of the three diagnostic tests applied in the aortic valve replacement patients. Five patients had positive myocardial scans, of whom four had peak values of creatine kinase (MB) activity of $>95 \mathrm{U} / 1$. All five patients with a positive scan had a negative electrocardiogram. One patient had an equivocal ( \pm ) scan but no other evidence of infarction. Five patients had peak creatine kinase (MB) activity ( $>95 \mathrm{U} / \mathrm{l}$. Four of these five patients had positive scans and all five a negative electrocardiogram. There was only one patient who had positive electrocardiographic evidence of infarction,

Table 1 Evidence of myocardial infarction in 25 patients undergoing aortic valve replacement

\begin{tabular}{llll}
\hline $\begin{array}{l}\text { Case } \\
\text { No }\end{array}$ & $\begin{array}{l}\text { Myocardial } \\
\text { scan }\end{array}$ & ECG & $\begin{array}{l}\text { Peak CKMB } \\
\text { activity }\end{array}$ \\
\hline 2 & - & + & - \\
3 & + & - & - \\
6 & + & $-\star$ & + \\
7 & + & $-\star$ & + \\
14 & + & - & + \\
18 & + & - & + \\
19 & - & - \\
24 & \pm & - & - \\
\hline
\end{tabular}

- , Negative; + , positive; \pm , equivocal; CKMB, creatine kinase MB isoenzyme.

$\star$ See text.
Table 2 Summary of results of technetium-99m pyrophosphate scans, creatine kinase isoenzyme (CKMB) measurements, and electrocardiography in indicating myocardial infarction in 25 patients undergoing aortic valve replacement

\begin{tabular}{llll}
\hline & \multicolumn{3}{l}{ No of positive results } \\
\cline { 2 - 4 } & Scans & $\begin{array}{l}\text { CKMB } \\
\text { activity }\end{array}$ & $\begin{array}{l}\text { ECG } \\
\text { changes }\end{array}$ \\
\hline Myocardial scans & 5 & 4 & 0 \\
Electrocardiographic changes & 0 & 0 & 1 \\
Enzyme measurements & 4 & 5 & 0 \\
\hline
\end{tabular}

and this patient had a negative scan and negative enzyme results. Two further patients had transient conduction defects of unknown significance.

In Fig. 1 the patients who had aortic valve replacement are classified as scan positive and scan negative, and enzyme activities for each of the four enzymes are compared using the Mann Whitney $U$ test of ranking. The probability values that the scan positive patients have significantly different peak enzyme activities from the scan negative patients are similar for each enzyme. There is no significant difference in the ability of each enzyme to discriminate between those patients who are scan positive and scan negative.

The timing as well as the magnitude of creatine kinase (MB) release is different between those

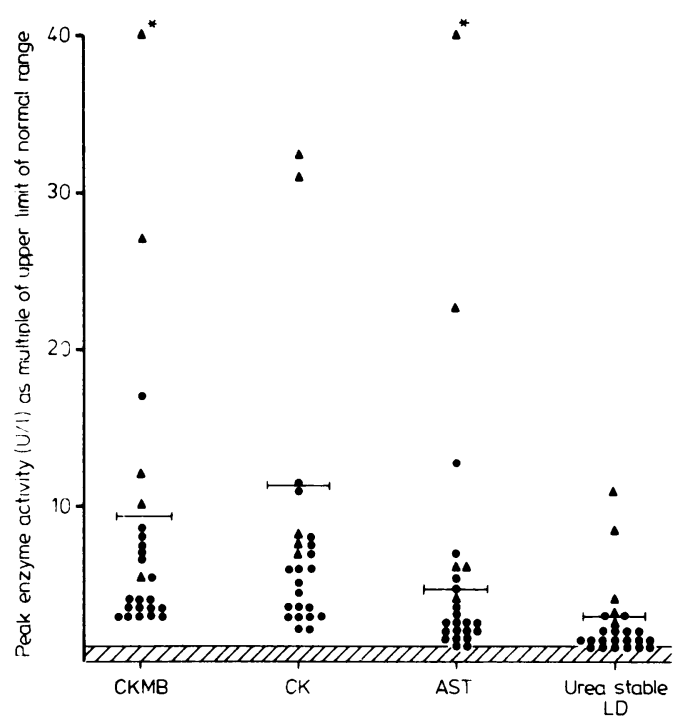

Fig. 1 Peak serum enzyme activities (expressed as a multiple of the upper limit of normal) for creatine kinase $M B$ isoenzyme $(C K M B)$, creatine kinase, aspartate aminotransferase (AST), and urea stable lactate dehydrogenase (LD). The two asterisked values represent $78.5 \times$ upper limit of normal for $C K M B$ (that is, $785 \mathrm{U} / \mathrm{l}$ ) and $78 \times$ upper limit of normal for AST (that is, $2340 \mathrm{U} / \mathrm{l})$. $\Delta$, scan positive; $\bigcirc$, scan negative. Bars represent mean values. 


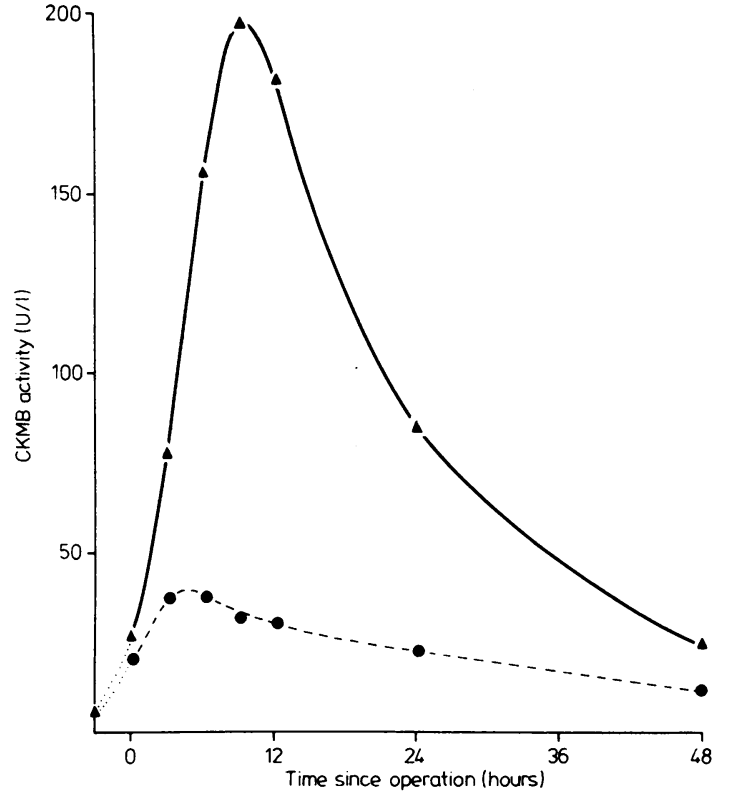

Fig. 2 Mean (geometric) creatine kinase MB (CKMB) activities at various times after operation in scan positive $(\Delta-\Delta)$ and scan negative $\left(\mathbf{O}_{-}-\mathbf{O}\right)$ patients.

patients who have concordant scanning and enzymatic evidence of infarction and those who have not (Fig. 2). Peak serum creatine kinase (MB) activity occurred between nine and 12 hours after bypass in those patients with both scanning and enzymatic evidence of infarction (as shown by the triangles) but occurred at about three hours in the remaining patients. Only creatine kinase (MB) values showed the pronounced qualitative difference in the "shape" of the release curve. There was no significant difference between those patients with both positive myocardial scans and positive enzyme results and the remaining patients as regards age, aortic cross clamping time, cardiopulmonary bypass time, or length of stay in hospital. Of the 24 survivors after mitral valve replacement, there was no evidence of injury on any of the diagnostic tests used.

\section{Discussion}

The mortality rates in this study of $4 \%$ for both aortic and mitral valve replacement are comparable to other series, ${ }^{11}{ }^{13}$ but examination of crude mortality rates is no longer sensitive enough to assess techniques of myocardial protection. ${ }^{3422}$ The technique of myocardial protection used in this study is similar to methods currently reported by others. ${ }^{6} 11$ Few such detailed parallel studies of technetium-99m pyrophosphate scanning, enzyme and isoenzyme release, and serial electrocardiography in groups of this size undergoing valve replacement have been reported.

In this study, in patients undergoing aortic valve replacement there was good correlation between myocardial scanning and enzymatic evidence of myocardial infarction. Four of the five patients with positive scans had enzymatic evidence of infarction. Similarly, four of the five patients with enzymatic evidence of injury had positive scans. The electrocardiogram did not correlate with either of the other indices of myocardial injury. Agreement between positive scans and positive enzymatic criteria was regarded as diagnostic of myocardial infarction, and therefore these four patients with both positive scans and positive enzyme results are considered to have had an infarction. All four of these infarct patients had severe aortic stenosis with left ventricular hypertrophy. Of these four patients, two had normal coronary arteries preoperatively at coronary arteriography. It is unfortunate that the other two patients did not undergo preoperative selective coronary arteriography, but this was not our practice at the time in elderly patients. To attempt to determine the state of the coronary arteries in these two patients exercise thallium scans were subsequently performed and were entirely normal. Infarction is, therefore, likely to be secondary to the global ischaemic insult of aortic cross clamping with inadequate protection of the concentrically hypertrophied left ventricle rather than due to regional hypoperfusion related to coronary disease and maldistribution of the cold cardioplegic solution.

None of the 35 preoperative scans was positive, which questions the need for such studies. Positive scans, however, have been reported in the absence of acute myocardial infarction in patients with unstable angina, ventricular aneurysm, non-aneurysmal wall motion abnormalities, cardiomyopathy, heavy valve calcification, and after cardioversion. ${ }^{1522}$ The patient with the positive postoperative scan but with no enzymatic or electrocardiographic evidence of infarction did not have a preoperative scan but did have heavy aortic valve calcification, evident on the preoperative chest $x$ ray film and at operation, with a peak systolic aortic valve gradient of $135 \mathrm{~mm} \mathrm{Hg}$. This may account for the false positive scan.

The evidence of the value of creatine kinase (MB) isoenzyme measurement in the diagnosis of peroperative infarction is conflicting. Peak enzyme activities of creatine kinase (MB) and hydroxybutyrate dehydrogenase were found by van der Laarse et al to be a good quantitative assessment of myocardial injury, ${ }^{26}$ but technetium-99m pyrophosphate scanning did not form part of that study. Olin et al reported creatine kinase (MB) measurement to be a good "marker" of 
ischaemic injury after aortic valve replacement and stated the need for frequent early sampling, ${ }^{11}$ but again technetium-99m pyrophosphate scanning was not undertaken. Klein $e t$ al, however, found that the measurement of peak creatine kinase (MB) release could not be used for the diagnosis of operative infarction and reiterated the difficulties of electrocardiographic interpretation. ${ }^{20}$ Righetti et al found creatine kinase (MB) release too sensitive a method of diagnosing operative infarction in a group of patients undergoing various cardiac surgical procedures. ${ }^{15}$ Selection of sampling times and difficulty in determining an enzyme value capable of distinguishing patients with infarcts from those without are arbitrary decisions which may account for some of these differences. The measurement of creatine kinase (MB) in this study did not discriminate appreciably better between patients with and without infarcts than did the more routinely measured (less cardiac specific) enzymes; this is in keeping with a previous study carried out by this group. ${ }^{19}$

Similarly, as in the previous study, ${ }^{19}$ the timing of peak serum creatine kinase (MB) activity occurs later in the infarct group than in the non-infarct group. The level of peak enzyme activity regarded as being indicative of myocardial infarction is arbitrary and we have used the mean $( \pm 2 S D$ ) (on the log transformed data) as the cut off point. This level for each enzyme was: total creatine kinase $1700 \mathrm{U} / 1$, aspartate aminotransferase $150 \mathrm{U} / 1$, and urea stable lactate dehydrogenase $800 \mathrm{U} / 1$. This figure will vary between different types of operation, between centres using different surgical techniques, and between laboratories using different enzyme methods. For routine purposes, it does not seem necessary to measure creatine kinase (MB) enzyme activity. The smaller rises in enzyme activity seen in all patients can be attributed partly to reversible myocardial damage and partly to the direct effect of the surgery itself. If the agreement of scanning and enzymatic evidence is accepted as indicative of myocardial infarction the incidence of myocardial infarction in this study was $16 \%$ for patients having aortic valve replacement and $4 \%$ (the one patient who died) for those having mitral valve replacement. This difference reflects the high risk of ischaemic injury to the hypertrophied left ventricle in patients with aortic stenosis. Technetium-99m pyrophosphate scanning and the measurement of plasma enzyme release were highly sensitive and specific in the diagnosis of operative myocardial infarction after valve replacement whereas the electrocardiogram proved unhelpful. A combination of these two techniques appears to be an accurate method of diagnosing peroperative myocardial infarction after cardiac valve replacement and can therefore be used for assessing the effectiveness of myocardial preservation techniques.

This study was carried out with the support of research grants from the Lothian Health Board and Scottish Hospital Endowment Research Trust.

\section{References}

1 Barnhorst DA, Oxman HA, Connolly DC, et al. Isolated replacement of the aortic valve with the Starr-Edwards prosthesis. A 9 year review. $\mathcal{F}$ Thorac Cardiovasc Surg 1975; 70: 113-8.

2 Levang $O$. Aortic valve replacement. A randomized study comparing the Björk-Shiley and Lillehei-Kaster disc valves. Pre-operative haemodynamic evaluation and early results. Scand $\mathcal{F}$ Thorac Cardiovasc Surg 1978; 12: 197-205.

3 McGoon DC. The quest for ideal myocardial protection [Editorial]. F Thorac Cardiovasc Surg 1980; 79: 150.

4 Bomfin V, Kaijser L, Bendz R, Sylvén C, Olin C. Myocardial protection during aortic valve replacement. Effects of mannitol in the cardioplegic solution on cardiac metabolism and enzyme release. Scand $\mathcal{f}$ Thorac Cardiovasc Surg 1981; 15: 129-33.

5 Stiles QR, Kirklin JW. Myocardial preservation symposium. F Thorac Cardiovasc Surg 1981; 82: 870-7.

6 Adams PX, Cunningham JN Jr, Trehan NK, Brazier JR, Reed GE, Spencer FC. Clinical experience using potassium-induced cardioplegia with hypothermia in aortic valve replacement. 7 Thorac Cardiovasc Surg 1981; 75: 564-8.

7 Karp RB, Lell W. Evaluating techniques of myocardial preservation for aortic valve replacement. Operative risk. f Thorac Cardiovasc Surg 1976; 72: 206-8.

8 Sapsford RN, Blackstone EH, Kirklin JW, et al. Coronary perfusion versus cold ischemic arrest during aortic valve surgery. Circulation 1974; 49: 1190-9.

9 Panetta F, Wong CCL, Dugdale LM, et al. Myocardial infarct imaging after cardiac surgery. Aust NZ $\mathcal{f}$ Surg 1979; 49: 228-35.

10 Neutze JM, Drakeley MJ, Barratt-Boyes BG, Hubbert $K$. Serum enzymes after cardiac surgery using cardiopulmonary bypass. Am Heart $\mathcal{F}$ 1974; 88: 425-42.

11 Olin CL, Bonfin V, Bendz R, Kaijser L, Ström SJ, Sylvén $\mathrm{CM}$. Myocardial protection during aortic valve replacement. Comparison of different methods by intraoperative coronary sinus blood sampling and postoperative serial enzyme determinations. $\mathcal{F}$ Thorac Cardiovasc Surg 1981; 82: 837-47.

12 Balderman SC, Bhayana JN, Binette P, Chan A, Gage AA. Perioperative preservation of myocardial ultrastructure and high-energy phosphates in man. $\mathcal{F}$ Thorac Cardiovasc Surg 1981; 82: 860-9.

13 Bonfin V, Kaijser L, Bendz R, Sylven C, Morillo F, Olin C. Myocardial protection during aortic valve replacement. Cardiac metabolism and enzyme release following continuous blood cardioplegia. Scand $\mathcal{F}$ Thorac Cardiovasc Surg 1981; 15: 141-7.

14 Clark RE, Christlieb IY, Ferguson TB, et al. The first American clinical trial of nifedipine in cardioplegia. A report of the first 12 months experience. $\mathcal{F}$ Thorac Car- 
diovasc Surg 1981; 82: 848-59.

15 Righetti A, O'Rourke RA, Schelbert M, et al. Usefulness of pre-operative and post-operative $T c-99 \mathrm{~m}$ (Sn)pyrophosphate scans in patients with ischemic and valvular heart disease. Am 7 Cardiol 1977; 39: 43-9.

16 Schroeder JS, Alderman EL, Harrison DC. Perioperative myocardial infarction during cardiac surgery. Adv Cardiol 1975; 15: 179-84.

17 Conti VR, Bertranou EG, Blackstone EH, Kirklin JW, Digerness SB. Cold cardioplegia versus hypothermia for myocardial protection. Randomized clinical study. $\mathcal{F}$ Thorac Cardiovasc Surg 1978; 76: 577-89.

18 Roe CR, Wagner GS, Young WG Jr, Curtis SE, Cobb FR, Irvin RG. Relation of creatine kinase isoenzyme MB to postoperative electrocardiographic diagnosis in patients undergoing coronary-artery bypass surgery. Clin Chem 1979; 25: 93-8.

19 McGregor CGA, Muir AL, Smith AF, et al. Myocardial infarction related to coronary artery bypass graft surgery. Br Heart F 1984; 51: 399-406.

20 Klein MS, Coleman RE, Weldon CS, Sobel BE, Roberts $R$. Concordance of electrocardiographic and scintigraphic criteria of myocardial injury after cardiac surgery. 7 Thorac Cardiovasc Surg 1976; 71: 934-7.

21 Klausner SC, Botvinick EH, Shames D, et al. The application of radionuclide infarct scintigraphy to diagnose perioperative myocardial infarction following revascularization. Circulation 1977; 56: 173-81.

22 Balderman SC, Bhayana JN, Steinbach JJ, Masud ARZ, Michalek S. Perioperative myocardial infarction: a diagnostic dilemma. Ann Thorac Surg 1980; 30: 370-7.

23 The Committee on Enzymes of the Scandinavian Society for Clinical Chemistry and Clinical Physiology. Recommended method for the determination of creatine kinase in blood. Scand f Clin Lab Invest 1976; 36: 711-23.

24 Mercer DW. Separation of tissue and serum creatine kinase isoenzymes by ion-exchange chromatography. Clin Chem 1974; 20: 36-40.

25 Brydon WG, Smith AF. An appraisal of routine methods for the determination of the anodal isoenzymes of lactate dehydrogenase. Clin Chim Acta 1973; 43: 361-9.

26 Van der Laarse A, Davids HA, Hollaar L, Van der Valk EJM, Witteveen SAGJ, Hermens WT. Recognition and quantification of myocardial injury by means of plasma enzyme and isoenzyme activities after cardiac surgery. $\mathrm{Br}$ Heart $\mathcal{F} 1979$; 41: 660-7. 